\title{
WALK BOLDLY IN THE NEW LIGHT
}

\author{
Jeremy Hanshaw
}

\section{INTRODUCTION}

To blindly fall in love with Narrative Inquiry before collecting data, to attempt to legitimate its usefulness, is an assertion often made of the Narrative Researcher (Kim, 2016). This is exactly what I aim to do in this paper: the stories are the data. In this article I will be exploring the trajectory of my professional practice journey through Critical Incident Analyses Narrative Inquiry in order to discover and uncover my Frame of Practice. I hope that, in so doing, I will contribute to an understanding of how Narrative Inquiry can be a useful tool to describe the journey of the learner and the practitioner.

I make no attempt to hide my love for Narrative Inquiry; the freedom it has afforded me to explore critical incidents and instances - stories which, though individual, form part of a whole. As well as to uncover my Frame of Practice, I aim in this paper to make a contribution to presenting Narrative Inquiry as a useful and, indeed, serious means of revealing verisimilitudes of possibilities. The "complexity of some lived moments" are not conveyed with theories. "You don't do that with a system of ideas. You do it with a story" (Coles, 1989, p. 128). Narrative Inquiry will enable these stories that might otherwise have fallen between the cracks.

Research "cannot be parcelled-up into neat little chunks, each phase done and stored away" (Trahar, 20 I I, p. 38). Nor can the critical incidents recorded in this paper or the landing places that they bring me, inevitably, to arrive at: they will be in many ways inseparable from themselves and from each other.

The stories may be polemic and evocative: "A critical event as told in a story reveals a change of understanding or worldview by the storyteller" (Webster \& Mertova, 2007, p. 73).

It may be that only the penultimate or the ultimate incident provides a reflexive view of the ultimate (or penultimate) learnings and landing places - the "denouement of the episode and understanding of the new action can draw upon previous understanding," new world views that are "different from all that have gone before" (Polkinghorne, 1995, p. 8).

That will be for you, the reader, to decide.

This work is based on my reflection on action (Boud and Walker, 1998) in the mode of this narrative.

\section{METHODOLOGY}

In this paper I use Critical Incident Analyses Narrative Inquiry, whereby I explore critical incidents in my life in the form of stories. These stories aim to uncover landing places in my professional practice, arrived at through the professional and personal learning that emerges from the narrative. My paper attempts to contribute to the "effort to remove the distance between theorizing and reality" (Kim, 20I6, p. 4I). Only then can we learn from the empathy generated from the human experience, and have a greater impact on social justice in our striving for human advancement. 


\section{STORY I - NO PASSENGERS}

LONDON. It was quite extraordinary that I should ever go to university. When I was I5, my parents considered opening a shop, so that when I left school at 16 with no qualifications, I would have a vocation: a means of making a living. Not enthralled at this prospect, I 'knuckled down,' "put my head down,' 'got on with it.' I arrived at university in possession of some very mediocre qualifications, and wholly unaware that I was embarking on an intellectual quest following some of the greatest names in history. TS Eliot and JRR Tolkien were two of them, neither of whom had been to my institution; but they had both taught Michael, my theology tutor. I was, therefore, touched by their words through his.

Michael told me that he once asked Professor Tolkien (pronounced Tolkein), what the Hobbit represented, to which Professor Tolkien succinctly replied, "Michael, the Hobbit is the Hobbit."

At the college inaugural dinner my personal tutor did not show; we sat together as a tutorial group wondering who David was. David was not someone who liked inaugural dinners. However, David liked well-written essays and he gave me my first 'aha moment' in tertiary education, and one of the most important.

I was reading David my essay on "The Phenomenology of Religion" standing, just, in his office overcrowded with books - towers of books, for there was not enough space on the shelves. David was looking out the sash window at the London grey.

"Stop there," he said. "That's clumsily expressed."

"Perhaps so," I replied. "But you know what l'm saying."

"Jeremy," he said, "how you say it is what you say."

How you say it is what you say. It's only ever what you say. There is no, "I mean this but I said that." What you say is what you say. It's as simple as that. From that point onwards, I not only said what I meant, for that is what you say, but I took pride in my words; I no longer separated what you say and what you mean. They are inseparable: one and the same.

I later reinforced this critical incident when writing my final-year dissertation on "Orwell and New Journalism." I critiqued Orwell's journalism for The Manchester Evening News and The Herald and Tribune, among other 'rags', through (what I now realise one terms) the interpretive lens of Harold Evans' tome, Newsman's English. In it, he remarks that in journalism, "Every word is a vehicle for precise communication: there is room for no passengers" (Evans, 1972).

This statement has become one of my frames of practice: I am a scribe, a man of words who takes pride in the words I choose, and the way I convey my thoughts. This is important to my practice because as a practitionerresearcher, I word my world - and how I do that is what I do.

\section{STORY 2 - SINGLE TO WWWWWWATERLOO PLEASE}

The City Literary Institute, The City Lit, levels whoever walks through the door.You might be a chartered surveyor attending a pottery class thirsty for a coffee, a special-needs learner determined to give the right money and count the change, or a person with a stammer with a mission to maintain eye contact when ordering: the canteen queue at The City Lit is a leveller.

I attended The City Lit because, under pressure, my stammer produced speech at about the rate of three words per minute. So I learned to speak again. I became consciously aware of every sound I made, and I developed a thick skin: I became desensitised to my stammer. 
It is unusual to wait for a bus you have no expectation of catching. I waited for the I 88 bus to Euston, with the intention of asking the driver if he was going to Waterloo, the opposite direction. Knowing he wasn't, I also knew I need not catch the bus. My mission, which I had chosen to accept: to look him, or her, in the eye, to maintain unswerving eye contact, and to ask, "Are you going to WWWWWWWWaterloo?" knowing they didn't. This I did. The driver was really patient. There was no drama. I felt triumphant and waited for the next bus to ask the same. This was a desensitisation exercise and an exercise in voluntary stammering.

Voluntary stammering is the art of stammering on purpose. It increases fluency because it increases openness about stammering (Fry, 2005): stammering happens most when I try to not stammer, and least when I do so on purpose. As a practitioner in the classroom, assuming the role of teacher, my stammer is hardly apparent. When a learner catches me off guard in the corridor and asks me to deliver fluent speech to order, I am strangulated in my words.

This relates to my professional practice because I am an imposter: a person with a stammer who masquerades as fluent. Perhaps it is because of the importance of the word - spoken and written - to my frame of practice, that I have a stammer at all. If I was a footballer, it would be my left leg that pained me.

My stammer is one of my frames of practice. It has taught me much: not least, that appearances can be deceptive - an appreciation of which I strive to show to others. It has also taught me that I will not encounter Laistrygonians, Cyclops and wild Poseidon as long as you "keep your thoughts raised high" (Cavafy, I9 I I, v. I).

It's also the only reason I am not prime minister. What other reason can there be?

\section{STORY 3 - RAG DOLLS AND PLASTIC BAGS}

NANCHANG. Warm; warm; warm; warm and clammy; warm; warm; ice cold. Someone had not made it through the night, as the morning hand on foreheads revealed. Wrapped tightly in a blanket with everything to keep her warm, except love, and a mother, and a reason to live. Eyes milky and unstaring. A room with 50 cots in rows, the contents wrapped in pink and lemon and abandoned. China's daughters - not wanted. Sons look after parents better than their female siblings - or such was the perception in one-child-policy China (Leung, 1997).

We used to visit the orphanage weekly and play with the fitter ones; the ones up for adoption. The less fit, or the disabled, or the albino, or the crippled, or the old, or the insane were housed in Dickensian quarters across the yard. The fit ones were in a colourful playroom with toys they never played with, except when we were there. At other times they were tied to their chairs, or would die in their cots. Crying out for "Mama, Mama, Mama." But Mama was not there. Mama had abandoned the unwanted daughter of China. Mama had travelled to the city to have her baby, desperate for a son, for her family would never let her keep a little girl. That little girl now tied to a chair, crying to her Mama, in a misty paddy field, in south-east China, where Mao had declared her people had stood up - where were her people now? Maybe she will be one of the lucky ones, snapped up by a family from Europe or North America. One of China's wanted daughters. The story eventually broke in The Atlantic with a piece titled, "In a Chinese Orphanage" (Thurston, 1996).

The little empress I had encountered that morning was lifted up like a rag doll by her upper garment, put in a plastic bag like a piece of rubbish and taken down to the incinerator. A future, a life, a daughter. Incinerated with the garbage.

This critical incident impressed upon me how cheap life had become in this part of the world. I, to the contrary, was loved into this world. Wanted by parents who cared for me deeply until their dying breaths. What kindnesses had occurred between my first breath and their last. I sleep soundly for knowing I was wanted, loved and cherished by two great people. By three. By more. I could not hold back the tears as I sobbed for this daughter of China, and for her mother, who must have wanted, whatever she had been forced to do, much more for her daughter than this. No doubt she would think of her often, wonder where she might be, muse whether the woman who walked past her 
at the market was her.The girl on the train. The factory worker. A lifetime of cruel separation. At least the daughter's pain was short; like her life. The mother's sentence will last until her own dying breath.

My first experience in China (1993-96) built resilience. It demonstrated to me that I have a skin colour - being white is not no colour - and the bricks that were thrown at me on the street reflected that skin colour, as they bounced off it. I built resilience to the shouts and the slurs, if not to the bricks, learned to walk around the fights and the riots, and developed my own transcultural competence, a third culture (Browaeys \& Price, 2008) - which was not the culture I was from, nor the culture where I now was, but the culture of me in that culture. And I developed a healthy tolerance for ambiguity, which is critical to achieving transcultural competence (Browaeys \& Price, 2008). Not knowing what on earth is going on for much of the time is the natural domain of the transculturally literate.

I am, therefore, a practitioner who has experienced agony at the suffering of others; developed resilience, enabling me to continue practising despite horror; and nurtured cultural competence to be able to work across cultures - a cultural worker (Giroux, 1992).

\section{STORY 4 - REST PEACEFULLY IN OUR HEARTS}

HAYLING ISLAND. When my mother gave her last breath, my sister thanked Mum for giving her me: her little brother. A few weeks later, that little brother spoke at Mum's funeral of how we had received a card from a friend that simply said, "May she rest peacefully in your hearts." For that is what she does. And I said that it is our greatest wish that she should rest peacefully in yours. And so she does.

PORTSMOUTH. When my father gave his last breath, I was not there. I received the call. Some weeks later, at his service, I made the important observation that there had been two children with very different childhoods: the one who was planned, and the one who was not; the one whose parents sat with them outside the pub, and the one whose parents left them sitting out alone; the one who went to university, and the one who left school at I4; the one who was cherished, and the one who was not. This treatment left a shadow on my father's heart, which was evident in his later years, which were not very happy ones. However, he made possible for me everything that was impossible for him.

A very central part of my frame of practice is that I am grateful for the opportunities I have had in life; that those that pass before us rest peacefully in our hearts; that no one is self-made; that there are always reasons to be grateful; that every day I wake up alive is a good day.

\section{STORY 5 - SUPER-COMPLEXITIES OFTHE MODERN INSTITUTION}

LONDON. University Academic Board: it is decided to lower the entrance requirements to increase overseas recruitment. The result is not as planned: fewer students are recruited over the next 18 months than during the previous period. Therefore, the decision is taken to lower them further: a similar result - recruitment drops.

Senge (1990) argues that time is the most insidious cause of non-systems thinking, and the greatest evidence of it is ever greater and greater need for the same solution. Here was a clear example and consequence of non-systems thinking: a greater and greater need to reduce the entry requirements to programmes had the antithetical result to the one desired. In a world where cause and effect are very subtle and occur over time (Senge, 1990), it is easy to fail to understand the true causes and effects of actions, of non-systems thinking. However, if Senge's premise is to be believed, it is likely that non-systems thinking was what we were engaged in.

Investigations led us to believe that by lowering the entrance requirements, an increase in programme failures had resulted in the institution gaining the spurious reputation of a place that was easy to enter, but impossible to graduate from. This resulted in the drop in student recruitment. 
When I was chief executive of a new UK university exam board, we experienced huge problems in getting our ESOL qualifications accredited by the regulator. As CEO, I led on understanding the pedagogic issues we faced and the political will behind them, in order to change the outcome for the betterment of the business. Schön (1983, p. 134) reflects on this: "When the practitioner tries to solve the problem he has set, he seeks both to understand the situation and to change it."This I did, with success: the qualifications were accredited.

An important component of my frame of practice is my ability to take a theory of action to a problem, to detect crucial errors (Schön, 1983), and engage in organisational learning (Senge, 1990) to develop a solution, which in turn will contribute to the learning of the organisation. My heathy tolerance of ambiguity serves this, enabling me to identify patterns of reflection, where doing and thinking are complementary (Schön, 1983); and just as the "practitioner becomes aware of the possibility of alternative ways of framing the reality of his practice" (Schön, 1993, p. 310 ), so do I, in my reflective practice. This takes courage, to "make a slit in the umbrella ... [to] tear open the firmament itself, to let in a bit of free and windy chaos and to frame in a sudden light a vision that appears through the rent ..." (Deleuze \& Guattari, 1994, pp. 203-204). Such "windy chaos" is an inevitability in this super-complex world. However, my willingness to engage in such tempestuous strategic meteorology resulted in the examinations board becoming a fully accredited and regulated awarding body in the UK, exceeding its targets in the first few years.

These anecdotes demonstrate that systems thinking is one of my frames of practice, as it enables me to attempt to understand the super-complexities of the modern institution and its place in a global context. Many subtle causes and effects interplay with many internal and external sources to result in a super-complex phenomenon that I strive to understand. An understanding of the 'early signs' of non-systems thinking, we can call them - the ever-enhanced need for the same solution - enables me to identify non-systems practice before it continues for very long; and courage provides the capacity to correct it, to take action and implement the corrective measure, if required.

\section{STORY 6 - A ONE-PAGER}

BANGKOK. Managing the training of more than 15,000 secondary and primary teachers in Thailand over two years resulted in some concise framing of my pedagogic and andragogic practice. Having to convey complex learning and teaching concepts to those who often had limited English, and support trainers in doing the same, resulted in the ability to produce 'one-pagers' of teaching practice and methodology that were easily digested by Thai teachers. Even minefields such as learner and teacher interaction and classroom management were simplified into areas of concise consideration such as the Activity Cycle (British Council, 2016). I used the tacit knowledge of the classroom practitioner to re-frame my practice into patterns of reflection (Schön, 1983) that were relatable to Thai teachers in their context. I used my transcultural competence to convey the messages, often employing my third culture (Browaeys \& Price, 2008) to express these pedagogic learnings to the trainers, as I operated as manager and trainer within the ambiguous space of the 'foreign' classroom. During this time, I crafted my skills at being a manager who engaged in the pastoral as well as professional care of my colleagues, with managers, trainers (some of whom were also managers) and teachers: learning from complementary doing and thinking (Schön, 1983), which was no more apparent than when demonstrating good and best practice, managing and teaching by example.

This episode demonstrates how I can operate as manager and trainer within the intervention space, use my tacit knowledge and build new skills to re-frame my practice according to the needs of the training audience, whether fellow manager, native speaker trainer or second language teacher, and practice by example for a variety of audiences.

\section{HERE AND NOW, NOW AND THEN - THE LAND, THE SEA AND THE SKY}

DUNEDIN.The bird with the aluminium wings brought me to this land: the Land of the Waters of the Green Stone; to these shores of emerald hills and chaotic seas. What a pleasure it is as "you enter harbors you're seeing for the first time" (Cavafy, 19| I, v. 2). 
As a nomadic subject practitioner, I have the opportunity to capstone all that I have learned over more than 25 years; "But don't hurry the journey at all. Better if it lasts for years" (Cavafy, 191 I, v. 3) in the context of learning, teaching and assessment, global engagements and micro-credentialing at Otago Polytechnic. The opportunity is not only as practitioner, but also as researcher, undertaking the Doctor of Professional Practice at Otago Polytechnic. I will need to use my frame of practice, especially my tolerance for ambiguity, to complete this journey.

Uncovering and considering such ambiguity is something Narrative Inquiry can do so well as, hopefully, these stories have told us.

As I walk through the clouds of Mount Cargill, though I know there is a mountain there, I cannot see it yet. I hope the cloak will one day reveal that which it obscures. On the walk up the mountain, I cross many streams; I change my frames of practice. However, it is important I let such now redundant frames go. "I shall show you how the Dhamma is similar to a raft, being for the purpose of crossing over, not for the purpose of grasping ..." (Edelglass \& Garfield, 2009, p. 83).

Some of what has served me so well on the journey I no longer need: the frameworks of the language teacher, the phonologist, the grammarian, even the manager. Compared with advanced andragogic practice, some of these frames can seem poor, simplistic in comparison. However, lthaka reminds us:

Ithaka gave you the marvelous journey.

Without her you wouldn't have set out.

She has nothing left to give you now.

And if you find her poor, lthaka won't have fooled you.

Wise as you will have become, so full of experience,

you'll have understood by then what these Ithakas mean

(Cavafy, 1911, w. 4 and 5).

And I thank them.

It is only at this moment, this denouement, do I see my stories so uniquely: tidy and yet untidy, masquerading as fluent.

So where have we landed in this penultimate and possibly ultimate moment?

\section{FRAME OF PRACTICE}

The foregoing leads me to this new understanding of all that has gone on before. I am an educator and a learner; a pedagogue / andragogue subject practitioner nomad; a man of words, who masquerades as fluent; I stammer; I am resilient, despite challenges in speech and circumstance; I am transculturally competent, with a healthy tolerance for ambiguity; I strive to practice by example, as teacher, trainer, tutor or mentor; I am grateful for family, friends, opportunities, education and this opportunity; I am grateful right now; I can be a systems thinker who attempts to understand the complexities of the modern world, though these days I prefer to use stories to uncover the unique human experience of people's encounter with, and memories of, them, so that looking backwards, we may go forwards; I have the courage to do what needs to be done, when it needs to be done, by whom it needs to be done; I am a practitioner-researcher; I am researched.

I now have an image in my mind of the view from the mountain: how the clouds might pass. The tools that I will need for that climb will be the subject of the next chapter of this journey.

"We shall not cease from exploration, and the end of all our exploring will be to arrive where we started and know the place for the first time" (Eliot, 1942). 
I am grateful for this opportunity. And I will be again.

Walk boldly in the new light.

\section{CONCLUSION}

A Frame of Practice has emerged through the stories told in this paper. It is hoped that as well as producing a clear professional practice framework, this paper contributes to the appreciation of Narrative Inquiry as a means of doing so, and of uncovering verisimilitudes of subtle phenomena through the lens of human experience and story.

Jeremy Hanshaw is a learning and teaching specialist at Otago Polytechnic and a Fellow of the Higher Education Academy. Based in Bangkok, Thailand, prior to Covid- 19, Jeremy travelled regularly to New Zealand as a specialist visiting academic. He continues to work remotely for Otago Polytechnic, where he is also undertaking the Doctor of Professional Practice degree.

Boud, D., \& Walker, D. (2006). Promoting reflection in professional courses: The challenge of context. Studies in Higher Education, 23(2), 191-206.

British Council (2016). Teach English: A resource book for primary teachers. Bangkok, Thailand: Author.

Browaeys, M., \& Price, R. (2008). Understanding cross-cultural management. London, UK: Pearson Education.

Cavafy, C. P. (19|I). Ithaka. Retrieved from https://www.poetryfoundation.org/poems/5 I 296/ithaka-56d22eef9 I7ec.

Coles, R. (1989). The call of stories: Teaching and the moral imagination. Boston, MA: Houghton Mifflin..

Deleuze, G., \& Guatari, F. (1994). What is philosophy? London, UK:Verso.

Edelglass, W., \& Garfield, J. L. (2009). Buddhist philosophy: Essential readings. Oxford, UK: Oxford University Press.

Eliot, T. S. (1942). Little Gidding. Retrieved from http://www.columbia.edu/itc/history/winter/w3206/edit/tseliotlittlegidding.html.

Evans, H. (1972). Newsman's English. Amsterdam, Netherlands: Elsevier Science \& Technology Books.

Fry, J. (2005, June). The cognitive model of social anxiety and its application to stuttering. Paper presented at the 7th Oxford Dysfluency Conference, Oxford, UK.

Giroux, H. (1992). Border crossings: Cultural workers and the politics of education. London, UK: Routledge.

Kim, J. H. (2016). Understanding narrative inquiry. London, UK: Sage.

Leung, J. C. B. (1997). Family support for the elderly in China. Journal of Aging \& Social Policy, 9(3), 87-1 01.

Polkinghorne, D. E. (1995). Narrative configuration in qualitative analysis. International Journal of Qualitative Studies in Education, 8(I), $5-23$.

Senge, P. (1990). The fifth discipline:The art and practice of the learning organisation. London, UK: Random House Business Books.

Schön, D. A. (1983). The reflective practitioner: How professionals think in action. Oxford, UK: Routledge.

Thurston, A. (1996, April). In a Chinese orphanage. The Atlantic. Retrieved from https://www.theatlantic.com/magazine/ archive//996/04/in-a-chinese-orphanage/376563/.

Trahar, S. (201 I). Developing cultural capability in international higher education: A narrative inquiry. Oxford, UK: Routledge.

Webster, L., \& Mertova, P. (2007). Using narrative inquiry as research method: An introduction to using critical event narrative analysis in research on learning and teaching. Oxford, UK: Routledge. 